Ophthalmologe 2014 · 111:982-982

DOI 10.1007/s00347-014-3132-y

Online publiziert: 19. Oktober 2014

๑) Springer-Verlag Berlin Heidelberg 2014

A. Vogel ${ }^{1,2} \cdot$ S. Freidank ${ }^{2} \cdot$ N. Linz $^{1}$

${ }^{1}$ Institut für Biomedizinische Optik, Universität zu Lübeck

2 Medizinisches Laserzentrum Lübeck GmbH

\title{
Erratum zu: Alternativen zur Femtosekundentechnologie. UV-Subnanosekundenpulse und Ringfoki für LASIK-Flaperzeugung
}

In diesem Beitrag wurde die Legende der Abb. 6 unvollständig wiedergegeben.

Bitte beachten Sie die vollständige Legende.

\section{Korrespondenzadresse}

\section{Prof. Dr. A. Vogel}

Institut für Biomedizinische Optik

Universität zu Lübeck

Peter-Monnik-Weg 4, 23562 Lübeck

vogel@bmo.uni-luebeck.de
Die Online-Version des Originalartikels können Sie unter http://dx.doi.org/10.1007/s00347-0132994-8 finden.
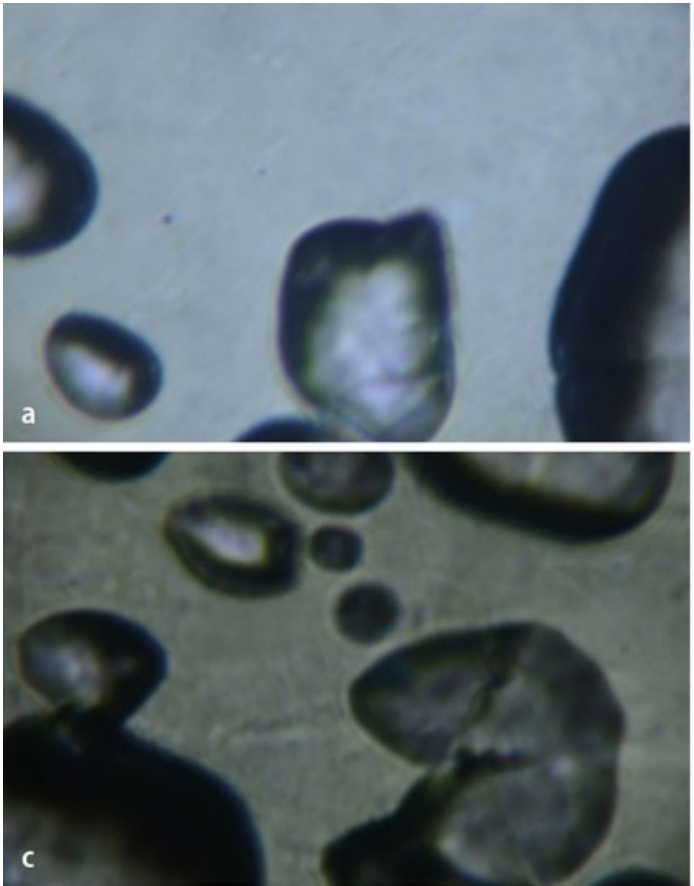
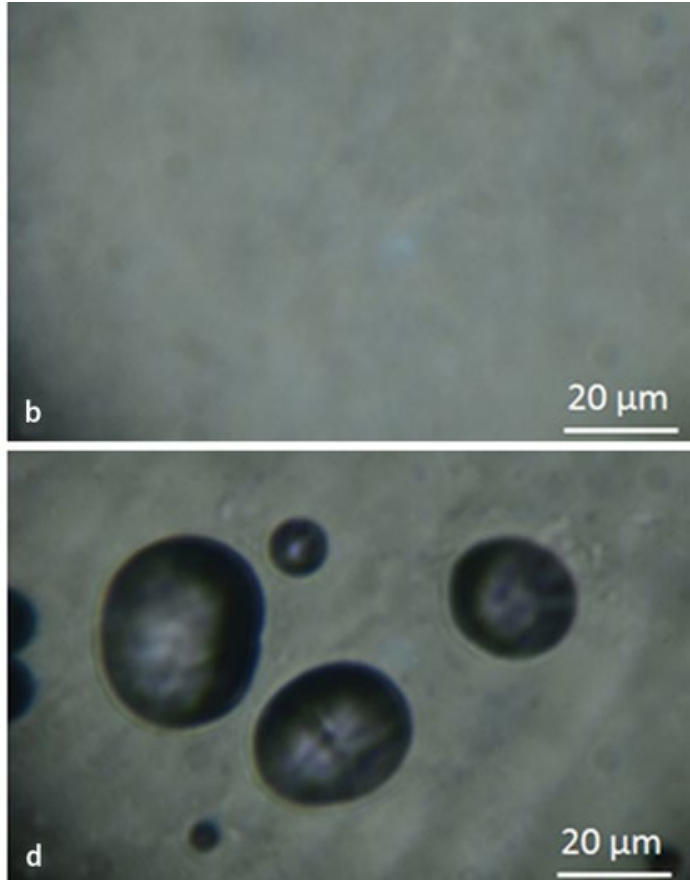

Abb. $6 \triangleright$ Blasen in der Schnittebene unmittelbar nach dem Flapschnitt mit verschiedenen Laserstrahltypen und Fokusabständen. a Gauss, $4 \mu \mathrm{m} \times 4 \mu \mathrm{m}$ b Vortex, $4 \mu \mathrm{m} \times 4 \mu \mathrm{m}$, c Gauss, $6 \mu \mathrm{m} \times 6 \mu \mathrm{m}$, d Vortex, $6 \mu \mathrm{m} \times 6 \mu \mathrm{m}$ 